\title{
INFLUÊNCIA DOS ATRIBUTOS FÍSICOS-MECÂNICOS DO SOLO NA ESTABILIDADE DO TALUDE DO BAIXO SÃO FRANCISCO
}

\author{
Influence of properties physicals-mechanicals in the stability of the slope in the lower São Francisco
}

\author{
Renisson Neponuceno de Araújo Filho ${ }^{1}$; Francisco Sandro Rodrigues Holanda 2*; Alceu Pedrotti ${ }^{2}$; Tiago de Oliveira \\ Santos $^{3}$; Janisson Bispo Lino ${ }^{4}$; Igor Pinheiro da Rocha ${ }^{5}$ \\ ${ }^{1}$ Pos Doutorando; Departamento de Energia Nuclear; Universidade Federal de Pernambuco (UFPE); e-mail: nepoaraujo@gmail.com \\ 2 Professor Doutor; Departamento de Engenharia Agronômica; Universidade Federal de Sergipe (UFS); e-mail: \\ fholanda@infonet.com.br (*AUTOR PARA CORRESPONDÊNCIA); alceupedrotti@gmail.com \\ ${ }_{3}^{3}$ Doutorando; Departamento de Agronomia; Universidade Federal Rural de Pernambuco (UFRPE); e-mail: tiagoosantos@yahoo.com.br \\ ${ }^{4}$ Engenheiro Agrônomo; Departamento de Engenharia Agronômica; Universidade Federal de Sergipe (UFS); e-mail: \\ janissonlino@gmail.com \\ ${ }_{5}^{5}$ Doutor; Departamento de Engenharia Agronômica; Universidade Federal de Sergipe (UFS); e-mail: rochaigor@hotmail.com
}

Artigo enviado em 02/05/2017, aceito em 10/09/2017 e publicado em 20/12/2017.

Resumo - O uso intensivo do solo das margens do rio São Francisco em seu baixo curso, exerce influência direta na sua degradação, potencializando a ocorrência da erosão marginal e, alterando a dinâmica fluvial. O objetivo deste estudo foi caracterizar os atributos físicos e mecânicos do solo em talude fluvial, relacionando-os com à susceptibilidade a erosão no Baixo curso do rio São Francisco. O ensaio experimental foi conduzido na margem direita do rio São Francisco, localizado no Município de Amparo do São Francisco, nordeste do Brasil, em talude com solo classificado como Neossolo Flúvico. Foram realizadas coletas de amostras indeformadas e deformadas de solo com execução de sondagem a trado, até o nível freático, e a caracterização dos atributos físicos e mecânicos do solo em laboratório. A predominância de camadas mais arenosas possibilitou maior ângulo de atrito interno e consequentes diminuição da coesão e redução da resistência ao cisalhamento levando a intensificação dos movimentos de massa. Os processos de saturação e secagem, através das elevações da cota do rio, comprometeram a estabilidade do talude. A granulometria do solo do talude é determinante para a suscetibilidade ao processo erosivo, e consequentemente para o comportamento mecânico desse talude.

Palavras-Chave- Cisalhamento direto, coesão, erosão marginal

\begin{abstract}
The use of the riparian areas with agriculture in the Lower San Francisco has a direct effect on the degradation of these resources causing, bank erosion, and the imbalance in the river dynamics. The objective of this study was to verify the influence of soil physical and mechanical attributes in the susceptibility of the riverbanks to erosion in the lower São Francisco. The experimental area was located in the municipality of Amparo de São Francisco, located in the state of Sergipe, northeastern Brazil, in soil classified as Neossolo Flúvico. Undisturbed soil and then deformed soil samples were collected to run the auger boreholes down up to water level representing the slope layers. The predominance of more sandy layers allowed a greater angle of internal friction and consequent reduction of cohesion and reduction of shear strength leading to the intensification of soil mass movements. Saturation and drying through the elevations of the river quota compromise the slope stability. The texture of the slope material is closely related to the erosion susceptibility and the riverbank soil mechanical behavior.
\end{abstract}

Keywords- Direct shear test, cohesion, riverbank erosion 


\section{INTRODUÇÃO}

Nos países em desenvolvimento a degradação dos recursos hídricos é um problema devido ao seu uso acelerado e de forma inadequada (XU, 2002). Nos agroecossistemas inseridos na região do Baixo São Francisco estão identificados vários pontos de ocorrência de erosão marginal, afetando diretamente a degradação desse recurso, rompendo o equilíbrio dinâmico da bacia (HOLANDA et al., 2007).

Os processos e alterações de origem natural ou antrópica que ocorrem nas bacias hidrográficas são refletidos diretamente nos cursos d'água, pois a qualidade de um curso d'água está diretamente relacionada com a qualidade ambiental da sua bacia hidrográfica como um todo (ROCHA et al., 2013), sendo o grau de degradação dos solos marginais um dos parâmetros mais utilizados para determinação da qualidade de um curso d'água, onde o processo erosivo tem grande importância.

O processo de erosão marginal é uma manifestação natural de reajuste dos canais, no entanto as ações antrópicas promovem aceleração e, induzindo com que a dinâmica fluvial se intensifique em busca de um novo equilíbrio. Em ecossistemas naturais, o processo erosivo ocorre de maneira harmoniosa onde o material erodido é depositado num local diferente da origem, mantendo assim a estabilidade da dinâmica fluvial (SILVA, 2010).

A alteração nas margens dos rios provocada pela ação humana seja pela operação de reservatórios ou pelo uso e ocupação inadequado do solo vem acelerando o processo de degradação ambiental. Estas alterações são responsáveis por inúmeros impactos ambientais, como o assoreamento dos rios, diminuição das áreas agricultáveis, aumento da ocorrência de inundações e ampliação das áreas atingidas por elas, além da possibilidade de redução da qualidade da água (HOLANDA et al., 2005).

Características como topografia, geomorfologia, presença de vegetação e atividade antrópica são fatores que interferem na estabilidade dos taludes, visto que elas modificam parâmetros como declividade, resistência ao cisalhamento, propriedades físicas, capacidade de retenção de água no solo e regime climático (HENSHAW et al., 2012; FAN; LAI, 2014). No entanto, quando as forças que atuam no solo são superiores às que promovem a estabilidade, o processo de desprendimento de massa de solo é iniciado e, consequentemente, ocorre erosão. A estabilidade dos taludes é dada pela relação entre as forças erosivas e os parâmetros que promovem a resistência do solo (XIA et al., 2008).

A resistência do solo ao cisalhamento é então definida como a tensão máxima cisalhante que o solo pode suportar sem sofrer ruptura, onde parâmetros como ângulo de atrito interno e coesão influenciam e alteram diretamente essa resistência, sendo estes parâmetros determinados por atributos físicos dos solos (BRAIDA et al., 2007).
Conhecer os atributos físicos e as propriedades mecânicas do solo de um talude fluvial, tais como: granulometria, estrutura, massas específicas, coesão e ângulo de atrito interno, bem como suas relações intrínsecas, são de suma importância para o melhor entendimento dos processos erosivos atuantes, e assim gerar informação visando o aumento da sua estabilidade. $\mathrm{O}$ objetivo deste estudo foi caracterizar os atributos físicos e mecânicos do solo em talude fluvial, relacionando-os com à susceptibilidade a erosão no Baixo curso do rio São Francisco.

\section{MATERIAL E MÉTODOS}

A amostragem de solo foi realizada em talude na margem direita do Baixo curso do rio São Francisco, localizada no Município de Amparo de São Francisco, Sergipe, nordeste do Brasil (coordenadas 36 53'22' W e $10^{\circ} 08^{\prime} 53^{\prime \prime}$ S). O solo da área experimental foi classificado como Neossolo Flúvico, de acordo com EMBRAPA (2013). A classificação climática segundo Koppen do trecho sedimentar do Baixo São Francisco é do tipo Am, clima Tropical megatérmico úmido e sub-úmido com temperatura média anual de $25^{\circ} \mathrm{C}$ e precipitação média anual é de 744,0 $\mathrm{mm}$ ano $^{-1}$ (CODEVASF, 2011).

A vegetação local é escassa e encontra-se, na sua grande extensão, desmatada para uso das terras com atividade pecuária podendo-se observar a presença de pastagens, inclusive nas margens do rio, assim como de algumas espécies frutíferas. O talude marginal estudado apresentou as seguintes dimensões: comprimento $100 \mathrm{~m}$, largura: $15 \mathrm{~m}$, perfazendo uma área total de 1.500,00 m², com altura média de $6,00 \mathrm{~m}$, inclinação média de $89,7 \%$, vazão média regularizada do curso d'água de $2.557 \mathrm{~m}^{3} \mathrm{~s}^{-1}$.

Os dados meteorológicos referentes à média mensal para o período de coleta no município de Amparo de São Francisco foram obtidos pelo INMET por meio da estação de superfície convencional, como precipitação: $260,3 \mathrm{~mm}$; temperatura máxima: $29,3{ }^{\circ} \mathrm{C}$; mínima: $22,4^{\circ} \mathrm{C}$; velocidade média do vento: $2 \mathrm{~m} . \mathrm{s}^{-1}$; umidade relativa do ar: $84,7 \%$.

\section{Coleta e análise do solo}

As amostras indeformadas foram coletadas em anel volumétrico com diâmetro de $0,15 \mathrm{~m}$ e altura de 0,20 $\mathrm{m}$ acondicionadas em cápsulas de alumínio, e as amostras deformadas por meio de sondagem a trado até o nível d'água. As coletas foram realizadas a cada $20 \mathrm{~m}$, a cada 20 $\mathrm{cm}$ até $6 \mathrm{~m}$ de profundidade, na área experimental, em conformidade com a NBR 9603 (ABNT, 1986), totalizando 5 pontos de coleta, com 6 repetições. Os ensaios de caracterização dos atributos físicos consistiram em análise granulométrica, densidade do solo (Ds), densidade de partículas sólidas do solo (Dp), umidade gravimétrica e limites de Atterberg, realizadas de acordo com as Normas Brasileiras NBR 6459 (ABNT, 1984a), NBR 6508 (ABNT, 1984b), NBR 7180 (ABNT, 1984c) e NBR 7181 (ABNT, 1988). 
As propriedades mecânicas coesão (c) e ângulo de atrito interno do solo $(\Phi)$ foram determinados por meio de ensaios de cisalhamento direto convencional não drenado. Para tanto, foi utilizada uma prensa de cisalhamento direto marca Wille Geotechnik, modelo LO 2900.

Avaliando as envoltórias efetivas do solo ao longo de uma superfície de interesse por meio do critério de MohrCoulomb, foram determinados o intercepto de coesão $(c)$, coeficiente de atrito $(\operatorname{tg} \Phi)$ e, por conseguinte, a tensão cisalhante $(\tau)$, através de corpos de prova obtidos por cravação de anéis metálicos nas amostras indeformadas dos solos, sendo extraídos quatro corpos de provas.

Assim, os corpos de prova foram submetidos às tensões normais de 50,100, 150 e $200 \mathrm{KPa}$, calculadas em função da Dp e da profundidade da amostra retirada (FAN; CHEN, 2010), que simulam os níveis médios de tensões geostáticas verticais efetivas para o talude estudado.

A velocidade horizontal de deslocamento utilizada para os ensaios foi de $0,50 \mathrm{~mm} \mathrm{~min}^{-1}$, sendo as leituras realizadas nos intervalos de $15,30,60 \mathrm{~s}$ e a cada $2 \mathrm{~min}$, com a amostra sendo saturada, sob inundação, aos $30 \mathrm{~s}$, respectivamente.

Para cada nível de tensão normal $\left(\sigma_{\mathrm{n}}\right)$ foi obtida a tensão cisalhante máxima $(\tau)$, usando a Equação de Coulomb, que permitiu obter o intercepto de coesão $(c)$ e o coeficiente de atrito $(\operatorname{tg} \Phi)($ Eq.1).

$$
\tau=\mathrm{c}+\sigma \operatorname{tg} \Phi(1) \text { Eq. } 1
$$

Os índices de vazios e grau de saturação, determinados no ensaio de cisalhamento direto, foram comparados na etapa inicial (fase de adensamento) e final (fase de cisalhamento) nas amostras.

\section{Análise estatística}

As amostras foram submetidas a ANOVA e, foi utilizada para determinar diferenças entre os atributos físicos das amostras submetidas ao ensaio de cisalhamento direto nas tensões de 50, 100, 150 e $200 \mathrm{kPa}$. O método usado foi a de diferença mínima significativa por Fisher's com o uso do programa Statistica 8.0 (STATSOFT INC., 2008).

\section{RESULTADOS E DISCUSSÃO}

\section{Caracterização do talude}

As características granulométricas observadas no talude fluvial apresentaram pequenas descontinuidades preenchidas com textura argilosiltosa nas camadas superiores e, nas camadas inferiores classificadas como franco-arenosa na área B1. As demais áreas (B2, B3, B4 e B5) foi enquadrada na classe textural arenosa (Tabela 1).

Esta disposição das camadas com granulometria distinta é explicada pelo processo de formação dos Neossolos Flúvicos, que consiste na deposição de sedimentos aluviais de origem variada, ao longo do tempo, sem uma relação pedogenética.
Tabela 1- Granulometria das amostras do Neossolo Flúvico coletadas no talude marginal do rio São Francisco, no município de Amparo do São Francisco, SE

\begin{tabular}{|c|c|c|c|c|c|c|}
\hline \multirow{3}{*}{ A } & \multirow{3}{*}{$\begin{array}{l}\mathrm{P} \\
(\mathrm{m})\end{array}$} & \multirow{3}{*}{$\begin{array}{l}\text { Umidade } \\
\left(\mathrm{Kg} \mathrm{Kg}^{-1}\right)\end{array}$} & \multicolumn{3}{|c|}{ SUCS $^{1}$} & \multirow{3}{*}{$\begin{array}{c}\text { Classe } \\
\text { Textural }^{2}\end{array}$} \\
\hline & & & Areia & Silte & Argila & \\
\hline & & & & $-\mathrm{g} \mathrm{kg}^{-1}$ & & \\
\hline \multirow{3}{*}{ B1 } & 1 & 0,104 & 64,4 & 486,6 & 449 & Argilosa \\
\hline & 2 & 0,089 & 109,8 & 469,1 & 421.1 & Argilosa \\
\hline & 3 & 0,023 & 616,8 & 214,3 & 168,9 & $\begin{array}{c}\text { Franco } \\
\text { Arenosa } \\
\end{array}$ \\
\hline \multirow{3}{*}{ B2 } & 1 & 0,088 & 26,1 & 558,8 & 415,1 & Argilosa \\
\hline & 2 & 0,079 & 9,7 & 504,3 & 486,0 & Argilosa \\
\hline & 3 & 0,006 & 860,8 & 48,2 & 91,0 & Areia \\
\hline \multirow{3}{*}{ B3 } & 1 & 0,066 & 80,5 & 501,7 & 417,8 & Argilosa \\
\hline & 2 & 0,091 & 107,9 & 446,6 & 445,5 & Argilosa \\
\hline & 3 & 0,003 & 824,4 & 73,3 & 102,3 & Areia \\
\hline \multirow{3}{*}{ B4 } & 1 & 0,059 & 36,6 & 470,2 & 493,2 & Argilosa \\
\hline & 2 & 0,084 & 102,6 & 458,2 & 439,2 & Argilosa \\
\hline & 3 & 0,01 & 846,3 & 56,2 & 97,5 & Areia \\
\hline \multirow{3}{*}{ B5 } & 1 & 0,046 & 9,0 & 515,3 & 475,7 & Argilosa \\
\hline & 2 & 0,065 & 42,4 & 490,7 & 466,9 & Argilosa \\
\hline & 3 & 0,002 & 913,2 & 51,1 & 35,7 & Areia \\
\hline
\end{tabular}

É possível observar a predominância da fração areia nas camadas mais profundas do talude, próximas ao nível d'água. Estas camadas apresentaram baixos teores das frações silte e argila, com exceção da área B1 na profundidade $3 \mathrm{~m}$, onde se observou $38,32 \%$ de partículas finas. Henshaw et al. (2012) atribuíram as perdas de solo à estratificação das margens em camadas coesivas e não coesivas. Assim, supõe-se que a presença de agregados com baixa estabilidade, principalmente nas camadas mais inferiores da margem estudada, possui correlação positiva com a erodibilidade do solo do talude.

As propriedades mecânicas de um talude estão ligadas à sua composição granulométrica, e a sua erodibilidade se apresenta inversamente proporcional aos teores de silte e argila. Desta forma, taludes que apresentam sedimentos com maiores porcentagens de silte e argila são mais resistentes aos processos erosivos (JULIAN; TORRES, 2006). Xia et al. (2008), afirmaram que a predominância da fração argila nas camadas inferiores dos taludes contribui para o aumento da resistência ao cisalhamento dos mesmos, devido à maior agregação fornecida ao solo na região onde o fluxo e refluxo das ondas ocorre com mais vigor, equivalente à base do talude.

A composição granulométrica do solo é um atributo físico que influencia indiretamente a resistência ao cisalhamento do solo, visto que ela altera a coesão das partículas e o ângulo de atrito interno (BRAIDA et al., 2007; PARKER et al., 2008).

O predomínio da fração areia provoca um acréscimo no ângulo de atrito interno e uma diminuição da coesão, aumentando a susceptibilidade do solo ao processo 
erosivo por meio da redução da resistência ao cisalhamento e consequente intensificação dos movimentos de massa. Essas faixas de frações granulométricas diferentes, provavelmente apresentarão uma anisotropia de resistência ao cisalhamento no sentido vertical e horizontal, constituída por parâmetros de coesão e ângulos de atrito distintos ao longo do talude, acompanhando essa variação granulométrica, consequência do processo de formação do solo. Silva e Carvalho (2007) observaram um aumento significativo nos valores de ângulo de atrito interno com o aumento dos teores da fração areia no solo.

A granulometria mais grosseira observada na base do talude (Tabela 1) quando associada com as demais variáveis atuantes no processo erosivo como, velocidade dos ventos e movimento de ondas, levam ao aumento do movimento de massa de solo. Esse movimento é intensificado devido à maior fração de areia presente na base do talude, visto que esse material confere baixa coesão ao solo e quando associado à ausência de cobertura vegetal estão mais sujeitos ás variações provocadas pelos processos de umedecimento e secagem ocasionados pelas variações na cota do rio, e assim proporcionando ao máximo a fácil desagregação do solo quando submetidas a pequenas forças.

As camadas superiores apresentaram maiores teores de finos, silte e argila, gerando um aumento na resistência do solo ao cisalhamento através da diminuição do ângulo de atrito interno e aumento da coesão (Tabela 1). Solos com predominância de partículas mais finas são mais resistentes ao processo de erosão fluvial, no entanto, são mais fáceis de serem degradados pelos demais processos erosivos. O aumento da resistência ao processo de erosão marginal se dá devido à possibilidade de formação de maior coesão entre as partículas de solo.

A umidade do solo representa um importante atributo físico para determinação da fragilidade dos taludes à erosão marginal. As camadas superficiais apresentaram os maiores teores de umidade (Tabela 1), possivelmente decorrente do maior teor de argila, e ou porosidade estrutural encontrado nestas amostras de solo. Essa porcentagem de umidade representa a umidade higroscópica que está intrinsecamente relacionada aos teores de silte e argila presentes no solo, evidenciando o aumento na capacidade de retenção de água quando há predominância de frações com maior superfície específica (CARDUCCI et al., 2011).

É possível afirmar que as amostras das camadas inferiores estudadas são mais susceptíveis à erosão quando comparadas às demais por apresentarem alta drenagem devido à sua composição granulométrica com predominância da fração areia, reduzindo a agregação das partículas do solo e não proporcionam coesão suficiente para manter as partículas unidas quando submetidas a forças externas.

Além disso, essas camadas são mais susceptíveis ao desprendimento das partículas de solo por estarem mais próximas ao nível d'água, onde sofrem frequentemente os efeitos da elevação da cota do rio, que aumenta o teor de água na matriz do solo e, consequentemente, eleva a lubrificação entre os seus constituintes. De acordo com
Parker et al. (2008), as partículas ficam mais distantes umas das outras, provocando redução na coesão.

Em taludes fluviais, esse fenômeno também é comum em trechos chamados de faixas de oscilação, onde alguns trechos do talude sofrem ciclos de secagem e umedecimento através das oscilações na cota do rio. Com a redução na coesão, a resistência ao cisalhamento do talude é diretamente reduzida, tornando a margem mais erodível, especialmente em períodos onde o fluxo do rio apresenta baixa carga sedimentar (XIA et al., 2008). Entretanto, Normaniza e Barakbah (2006) identificaram menor resistência ao cisalhamento em encostas com baixos teores de umidade.

Em geral, as amostras apresentaram elevado teor de finos, e reconhecidamente possuem maior capacidade de retenção de água. Contudo, a maior porcentagem de umidade apresentada na área B1 (Tabela 1), coletada na profundidade 1, pode estar atrelada aos elevados teores de matéria orgânica apresentados nos centímetros iniciais desta camada, originada da decomposição da serapilheira proveniente da densa vegetação presente neste ponto de coleta. Este resultado concorda com os achados de Yao et al. (2009), que identificaram, respectivamente, maiores teores de umidade e maior capacidade de retenção de água nas camadas mais superiores dos solos que apresentavam densa cobertura vegetal, devido ao denso sistema radicular presente nos solos onde a umidade diminuía com o aumento da profundidade.

Quando esta situação ocorre é possível que todo o talude passe a atuar numa condição de instabilidade, pois quando o solo, das camadas superiores do talude se encontram no estado saturado ocorre redução da altura vertical crítica do mesmo. Normaniza e Barakbah (2006) explicaram que quando o solo do talude está saturado, além do fluxo de água ser maior, ocorre um considerável aumento na densidade do solo, que eleva a carga real sobre as partículas inferiores, provocando aumento efetivo nas tensões cisalhantes, e consequentemente facilitando a ocorrência de falhas e movimentos de massa.

Situação semelhante foi observada por Xia et al. (2008) em um talude com predominância de finos (silte e argila), que teve sua altura vertical crítica reduzida de $6,6 \mathrm{~m}$, quando seco, a apenas $0,80 \mathrm{~m}$, quando saturado. Os autores relataram que o talude sofreu movimento de massa somente em função da saturação, sem a ação de forças externas.

\section{Análises do comportamento mecânico do solo em relação aos índices físicos}

Nas diferentes tensões, as quais as amostras foram submetidas foram constatadas diferenças significativa entre as áreas.

Estas diferenças apresentadas foram possivelmente, devido as diferentes características granulométricas das amostras de solo.

Esse fato promoveu comportamentos distintos de determinados parâmetros ao longo dos ensaios e nos seus limites. 
Tabela 2 - Média dos atributos físicos das amostras submetidas ao ensaio de cisalhamento direto nas tensões de 50, 100, 150 e $200 \mathrm{kPa}$

\begin{tabular}{|c|c|c|c|c|c|c|c|c|c|}
\hline Áreas & $\begin{array}{l}\text { (1) } \mathrm{TN} \\
(\mathrm{kPa})\end{array}$ & $\begin{array}{c}{ }^{(2)} \mathrm{DSI} \\
\left(\mathrm{g} \mathrm{cm}^{-3}\right)\end{array}$ & $\begin{array}{c}\text { (3)DSF } \\
\left(\mathrm{g} \mathrm{cm}^{-3}\right)\end{array}$ & $\begin{array}{l}\text { (4)IVI } \\
(\%)\end{array}$ & $\begin{array}{c}{ }^{(5)} \text { IVF } \\
(\%)\end{array}$ & $\begin{array}{c}{ }^{(6)} \mathrm{GSI} \\
(\%)\end{array}$ & $\begin{array}{c}{ }^{(7)} \mathrm{GSF} \\
(\%)\end{array}$ & (8) UI (\%) & $\begin{array}{c}\text { (9) UF } \\
(\%)\end{array}$ \\
\hline \multirow{4}{*}{ B1 } & 50 & $1,448 \mathrm{~b}^{(*)}$ & $1,475 \mathrm{~b}$ & $0,82 \mathrm{a}$ & $0,78 \mathrm{a}$ & $62,9 \mathrm{~b}$ & $100,3 \mathrm{~b}$ & $19,51 \mathrm{~b}$ & $29,88 \mathrm{a}$ \\
\hline & 100 & $1.428 \mathrm{~b}$ & $1.534 \mathrm{~b}$ & $0.84 \mathrm{a}$ & $0.71 \mathrm{a}$ & $58.9 \mathrm{~b}$ & $105.7 \mathrm{~b}$ & $18.85 \mathrm{~b}$ & $28.70 \mathrm{a}$ \\
\hline & 150 & $1.472 \mathrm{~b}$ & $1.585 \mathrm{~b}$ & $0.78 \mathrm{a}$ & $0.66 \mathrm{a}$ & $60.8 \mathrm{~b}$ & $103.4 \mathrm{a}$ & $18.20 \mathrm{~b}$ & $25.93 \mathrm{a}$ \\
\hline & 200 & $1.490 \mathrm{~b}$ & $1.580 \mathrm{~b}$ & $0.76 \mathrm{a}$ & $0.66 \mathrm{a}$ & $56.9 \mathrm{~b}$ & $102.5 \mathrm{a}$ & $16.54 \mathrm{~b}$ & $25.91 \mathrm{a}$ \\
\hline \multirow{4}{*}{ B2 } & 50 & $1.578 \mathrm{ab}$ & $1.615 \mathrm{~b}$ & $0.67 \mathrm{a}$ & $0.63 \mathrm{a}$ & $84.8 \mathrm{a}$ & $108.9 \mathrm{~b}$ & $21.63 \mathrm{a}$ & $26.21 \mathrm{a}$ \\
\hline & 100 & $1.567 \mathrm{a}$ & $1.631 \mathrm{a}$ & $0.68 \mathrm{a}$ & $0.62 \mathrm{a}$ & $83.2 \mathrm{a}$ & $102.9 \mathrm{~b}$ & $21.6 \mathrm{~b}$ & $24.14 \mathrm{~b}$ \\
\hline & 150 & $1.530 \mathrm{a}$ & $1.643 \mathrm{a}$ & $0.72 \mathrm{a}$ & $0.60 \mathrm{a}$ & $87.4 \mathrm{a}$ & $110.9 \mathrm{a}$ & $24.06 \mathrm{a}$ & $25.53 \mathrm{a}$ \\
\hline & 200 & $1.502 \mathrm{~b}$ & $1.632 \mathrm{~b}$ & $0.75 \mathrm{a}$ & $0.61 \mathrm{a}$ & $79.3 \mathrm{a}$ & $107.2 \mathrm{a}$ & $22.79 \mathrm{a}$ & $25.12 \mathrm{a}$ \\
\hline \multirow{4}{*}{ B3 } & 50 & $1.625 \mathrm{a}$ & $1.635 \mathrm{a}$ & $0.63 \mathrm{a}$ & $0.62 \mathrm{a}$ & $95.3 \mathrm{a}$ & $105.2 \mathrm{~b}$ & $22.79 \mathrm{a}$ & $24.77 \mathrm{~b}$ \\
\hline & 100 & $1.593 \mathrm{a}$ & $1.658 \mathrm{a}$ & $0.66 \mathrm{a}$ & $0.60 \mathrm{a}$ & $87.2 \mathrm{a}$ & $105.0 \mathrm{~b}$ & $21.95 \mathrm{a}$ & $23.83 \mathrm{~b}$ \\
\hline & 150 & $1.593 \mathrm{a}$ & $1.681 \mathrm{a}$ & $0.66 \mathrm{a}$ & $0.58 \mathrm{a}$ & $82.9 \mathrm{a}$ & $100.0 \mathrm{a}$ & $20.85 \mathrm{a}$ & $21.90 \mathrm{a}$ \\
\hline & 200 & $1.630 \mathrm{a}$ & $1.749 \mathrm{a}$ & $0.63 \mathrm{a}$ & $0.52 \mathrm{a}$ & $87.0 \mathrm{a}$ & $108.9 \mathrm{a}$ & $20.64 \mathrm{a}$ & $21.31 \mathrm{~b}$ \\
\hline \multirow{4}{*}{ B4 } & 50 & $1.737 \mathrm{a}$ & $1.757 \mathrm{a}$ & $0.53 \mathrm{~b}$ & $0.51 \mathrm{~b}$ & $97.9 \mathrm{a}$ & $110.2 \mathrm{~b}$ & $19.64 \mathrm{~b}$ & $21.37 \mathrm{~b}$ \\
\hline & 100 & $1.580 \mathrm{a}$ & $1.608 \mathrm{~b}$ & $0.68 \mathrm{a}$ & $0.65 \mathrm{a}$ & $94.5 \mathrm{a}$ & $112.4 \mathrm{a}$ & $24.34 \mathrm{a}$ & $27.74 \mathrm{a}$ \\
\hline & 150 & $1.564 \mathrm{a}$ & $1.650 \mathrm{a}$ & $0.70 \mathrm{a}$ & $0.61 \mathrm{a}$ & $85.5 \mathrm{a}$ & $109.8 \mathrm{a}$ & $22.60 \mathrm{a}$ & $25.37 \mathrm{a}$ \\
\hline & 200 & $1.541 \mathrm{a}$ & $1.664 \mathrm{a}$ & $0.73 \mathrm{a}$ & $0.60 \mathrm{a}$ & $82.6 \mathrm{a}$ & $107.8 \mathrm{a}$ & $22.62 \mathrm{a}$ & $24.35 \mathrm{a}$ \\
\hline \multirow{4}{*}{ B5 } & 50 & $1.560 \mathrm{ab}$ & $1.681 \mathrm{a}$ & $0.69 \mathrm{a}$ & $0.57 \mathrm{~b}$ & $83.9 \mathrm{a}$ & $125.0 \mathrm{a}$ & $22.01 \mathrm{a}$ & $26.99 \mathrm{a}$ \\
\hline & 100 & $1.599 \mathrm{a}$ & $1.716 \mathrm{a}$ & $0.65 \mathrm{a}$ & $0.53 \mathrm{~b}$ & $85.4 \mathrm{a}$ & $125.9 \mathrm{a}$ & $21.04 \mathrm{a}$ & $25.65 \mathrm{a}$ \\
\hline & 150 & $1.566 \mathrm{a}$ & $1.639 \mathrm{a}$ & $0.68 \mathrm{a}$ & $0.61 \mathrm{a}$ & $87.5 \mathrm{a}$ & $107.1 \mathrm{a}$ & $22.70 \mathrm{a}$ & $24.76 \mathrm{a}$ \\
\hline & 200 & $1.592 \mathrm{a}$ & $1.696 \mathrm{a}$ & $0.65 \mathrm{a}$ & $0.55 \mathrm{a}$ & $86.8 \mathrm{a}$ & $114.2 \mathrm{a}$ & $21.64 \mathrm{a}$ & $24.04 \mathrm{a}$ \\
\hline
\end{tabular}

(1)TN - Tensões Normais, (2)DSI - Densidade do Solo Inicial, (3)DSF - Densidade do Solo Final,(4) IVI - Índice de Vazios Inicial, (5) IVI - Índice de Vazios Final, (") GSI - Grau de Saturação Inicial, (") GSF - Grau de Saturação Final, ${ }^{(8)}$ UI - Umidade Inicial, (9) UI - Umidade Final. ${ }^{(*)}$ Letras diferentes representam diferenças significativas entre médias dentro de uma coluna para cada tensão de cisalhamento de Fisher após ANOVA.

As amostras coletadas apresentaram os menores valores médios do índice de vazios na fase final, ainda nessa fase apresentaram os maiores graus de saturação e densidade do solo na fase final do ensaio (Tabela 2).

No estado final do ensaio, o índice de vazios decresceu proporcionalmente com o aumento da tensão efetiva, para todos os corpos de prova testados, considerando que quando há um acréscimo de tensão aplicada a um corpo de prova, a água dos espaços vazios saiu e ocorreu redução do índice de vazios, indicando que, está havendo deformação na estrutura sólida do solo.

Mesmo variando nas tensões submetidas, os índices de vazios das amostras apresentaram valores médios próximos de 1, e estes valores ocorrem quando o volume de sólidos do solo é aproximadamente igual ao volume de espaços vazios. Proporcionalmente o grau de saturação obteve o mesmo comportamento, ou seja, quanto menor o índice de vazios maior foi o preenchimento dos vazios com água (ORTIGÃO, 1995).

As amostras das áreas B1 e B4 apresentaram índices de vazios distintos (Tabela 2). A amostra da área B1 apresentou o maior valor médio do índice de vazios, inicialmente com 0,842 e final 0,714.

Este maior valor médio encontrado para o índice de vazios, além de classificar o solo como solto e poroso, justifica o menor valor médio da densidade do solo encontrado.
A amostra da área B4 apresentou o valor médio menor de índice de vazios, com valor inicial de 0,535 e final de 0,517 e, ao contrário da amostra área B1, a sua densidade do solo apresentou maior valor.

Em concordância com Ribeiro et al. (2007), esse comportamento justifica o menor valor médio de densidade do solo encontrado para esta amostra, corroborando o resultado dos ensaios onde as amostras em todas as tensões, na fase inicial e final do ensaio, possuem o menor índice de vazios, e o maior densidade do solo.

O grau de saturação na fase final do ensaio apresentou-se maior que na fase inicial para todas as amostras nos quatro níveis de tensões testados (Tabela 2) em virtude da inundação do corpo de prova na fase de adensamento. Os valores do grau de saturação aumentaram em torno de um intervalo em média 3,88\% do estado inicial até o final do ensaio.

Após a ruptura, os corpos de prova apresentaram grau de saturação diferenciado (Tabela 2), resultado da heterogeneidade da granulometria das amostras. O grau de saturação apresenta proporcionalidade direta com a massa específica.

No estado final, a densidade do solo aumentou proporcionalmente ao aumento das tensões Normal aplicadas. Esse comportamento é consequência do aumento dos esforços para os quais o solo é solicitado e da diminuição do volume de solo no corpo de prova devido ao 
adensamento. Além disso, ocorreu aumento do valor da massa de solo proveniente do aumento da umidade.

As menores densidade do solo como observadas na amostra da área B1 também foram identificadas em experimentos conduzidos por Reinert et al. (2008), que afirmaram que essa possibilidade pode estar relacionada ao maior teor de matéria orgânica. Contudo, as amostras que apresentaram maior percentual de frações finas como a amostra da área B4, apresentaram os menores valores médio de umidade e os maiores densidade do solo, exceto a amostra da área B1 que apresentou menor valor médio de umidade e menor densidade do solo. Este comportamento pode estar relacionado com a presença de raízes no corpo de prova analisado.

$\mathrm{Na}$ fase inicial do ensaio, as amostras apresentaram os menores valores médios de umidade, encontrando-se não saturadas, densidade do solo menor e índice de vazio relativamente alto (Tabela 2). Possivelmente, a tensão Normal aplicada de $200 \mathrm{KPa}$ seja um valor de tensão maior do que aquele que efetivamente atua no talude, e parece que a atuação dessa pressão no corpo de prova confinado na câmara de cisalhamento do aparelho, diminui ainda mais o índice de vazios. O corpo de prova posteriormente inundado, não conseguiu absorver e tampouco percolar água ao longo de sua massa de solo. Possivelmente, ao invés de absorver mais água após a inundação, a água foi expulsa, enquadrando o solo em níveis de umidade menores do que as iniciais. Para as demais tensões, provavelmente a perda de umidade ocorreu devido ao manuseio da retirada do anel depois de realizado o ensaio, que inclusive influenciou o grau de saturação das amostras.

A variação da umidade desenvolve-se proporcionalmente em relação ao índice de vazios. É importante ressaltar que mesmo as amostras que apresentaram umidade elevada, a densidade do solo encontra-se baixa e o índice de vazios elevado, indicando que o solo está possivelmente no estado solto. Segundo Braida et al. (2007), o aumento ou redução da resistência do solo dependerá do balanço entre seus efeitos conjuntos sobre a densidade, os parâmetros de cisalhamento, a tensão capilar e o grau de saturação de água.

\section{CONCLUSÕES}

As características mecânicas do talude e a sua suscetibilidade ao processo erosivo estão intimamente relacionados com a granulometria do solo do talude.

A predominância de camadas mais arenosas possibilitou maior ângulo de atrito interno e consequentes diminuição da coesão e redução da resistência ao cisalhamento levando a intensificação dos movimentos de massa.

A saturação e secagem por meio da elevação da cota do rio comprometem a estabilidade do talude devido à diminuição da altura crítica vertical através da redução dos valores de coesão, indicando que a quantidade de água no solo tem alto grau de influência nos parâmetros mecânicos e pode melhorá-los ou não, pois existe um intercepto de coesão máximo para uma umidade ótima de coesão.

\section{REFERÊNCIAS}

ABNT - Associação Brasileira de Normas Técnicas. NBR 6459: Solo: Determinação do limite de liquidez. Rio de Janeiro: ABNT, 1984a. 6p.

ABNT - Associação Brasileira de Normas Técnicas. NBR 6508: Grãos de solos que passam na peneira de $4,8 \mathrm{~mm}$ : determinação da massa específica. Rio de Janeiro: ABNT, 1984b. 8p.

ABNT - Associação Brasileira de Normas Técnicas. NBR 7180: Solo: Determinação do limite de plasticidade. Rio de Janeiro: ABNT, 1984c. 3p.

ABNT - Associação Brasileira de Normas Técnicas. NBR 9603: Sondagem a Trado. Rio de Janeiro: ABNT, 1986. 6p.

ABNT - Associação Brasileira de Normas Técnicas. NBR 7181: Solo: Análise granulométrica. Rio de Janeiro: ABNT, 1988. 13p.

BRAIDA, J. A. et al. Coesão e atrito interno associados aos teores de matéria orgânica e de água de um solo franco arenoso. Ciência Rural, v. 37, n. 6, p.1646-1653, 2007.

CARDUCCI, C. E. et al. Modelagem da curva de retenção de água de latossolos utilizando a equação duplo Van Genuchten. Revista Brasileira de Ciência do Solo, v. 35, n. 1, p.77-86, 2011.

CODEVASF - Companhia de Desenvolvimento do Vale do São Francisco e Parnaíba. Projeto básico de proteção da margem direita do rio São Francisco no Perímetro de Irrigação Cotinguiba/Pindoba, $4^{\mathrm{a}}$ SR Sergipe. Brasilia: CODEVASF, 2011.696 p.

FAN, C.; CHEN, Y. The effect of root architecture on the shearing resistance of root-permeated soils. Ecological Engineering, v. 36, n. 6, p. 813-826, 2010.

FAN, C.; LAI, Y.F. Influence of the spatial layout of vegetation on the stability of slopes. Plant and Soil, v. 377, n. 1-2, p. 83-95, 2014.

STATSOFT INC. Statistica data analysis system version 8.0. Tulsa: Statsoft Inc., 2008.

HENSHAW, A. J.; THORNE, C. R.; CLIFFORD, N. J. Identifying causes and controls of river bank erosion in a British upland catchment. Catena, n. 1, v. 100, p. 107-119, 2012.

HOLANDA, F.S.R. et al. Análise multitemporal e caracterização dos processos erosivos no Baixo São Francisco sergipano. Revista Brasileira de Geomorfologia, v. 8, n. 2, p. 87-96, 2007. 
HOLANDA, F.S.R. et al. Riparian vegetation affected by bank erosion in the Lower São Francisco River, Northeastern Brazil. Revista Árvore, v.29, n.2, p.327-336, 2005.

JULIAN, J.P.; TORRES, R. Hydraulic erosion of cohesive riverbanks. Geomorphology, v.76, n.1, p.193-206, 2006.

NORMANIZA, O.; BARAKBAH, S.S. Parameters to predict slope stability - Soil water and root profiles. Ecological Engineering, v. 28, n. 1, p. 90-95, 2006.

ORTIGÃO, J. A. R. Introdução à mecânica dos solos dos estados críticos. $2^{\mathrm{a}} \mathrm{ed}$. Rio de Janeiro: Livros Técnicos e Científicos, 1995. 374p.

PARKER, C.; SIMON, A.; THORNE, C.R. The effects of variability in bank material on riverbank stability: Goodwin Creek, Mississippi. Geomorphology, v. 101, n. 4, p. 533-543, 2008.

REINERT, D. J. et al. Limites críticos de densidade do solo para o crescimento de raízes de plantas de cobertura em argissolo vermelho. Revista Brasileira de Ciência do Solo, v. 32, n. 5, p. 1805-1816, 2008.

RIBEIRO, K. D. et al. Propriedades físicas do solo, influenciadas pela distribuição de poros, de seis classes de solos da região de Lavras, MG. Ciência e Agrotecnologia, v. 31, n. 1, p. 1167-1175, 2007.

ROCHA, I. P. et al. Meteorological and hydrological variables on occurrence of river bank erosion along Lower São Francisco river. Revista Brasileira de Engenharia Agrícola e Ambiental, v. 17, n. 2 p. 137-144, 2013.

SILVA, A. J. N.; CARVALHO, F. G. Coesão e resistência ao cisalhamento relacionado a atributos físicos e químicos de um Latossolo Amarelo de tabuleiro costeiro. Revista Brasileira de Ciência do Solo, v. 31, n. 5, p. 853-862, 2007.

SILVA, L. C. Manejo de rios degradados: uma revisão conceitual. Revista Brasileira de Geografia Física, v. 3, n. 1, p. 23-32, 2010.

XIA, J. Q. et al. An analysis of soil composition and mechanical properties of riverbanks in a braided reach of the Lower Yellow River. Chinese Science Bulletin, v. 53, n. 15, p. $2400-2409,2008$.

XU, J. River sedimentation and channel adjustment of the lower Yellow River as influenced by low discharges and seasonal channel dry-ups. Geomorphology, v. 43, n. 1, p. 151-164, 2002.

YAO, S. et al. The effects of vegetation on restoration of physical stability of a severely degraded soil in China. Ecological Engineering, v. 35, n. 5, p.723-734, 2009. 